\title{
Egoistic and Nonegoistic Motives in Social Dilemmas
}

\author{
Michael Lynn and Andrew Oldenquist, Ohio State University
}

\begin{abstract}
Many of the world's problems (e.g., overpopulation, pollution, and the depletion of nonrenewable resources) may be characterized as social dilemmas. The solutions to social dilemmas, then, are very important. In this article, we argue: (a) that social psychologists have approached the problem of social dilemmas with an egoistic bias, (b) that this bias limits the number and types of solutions to dilemmas that psychologists investigate, (c) that egoistically based solutions to social dilemmas are not adequate in many real-world dilemmas, and (d) that viable solutions to these dilemmas may be found in nonegoistic motives.
\end{abstract}

Classical economic thought maintained that the individual's best interest also serves the best interest of society as a whole. The laws of the market (Adam Smith's "invisible hand") supposedly direct selfish concern toward the interests and demands of society. Unfortunately, this harmonious view of the individual's relationship with society is no longer tenable. The conceptual work of modern scientists such as Olson (1965) and Hardin (1968) clearly demonstrates that an individual's best interest can, and frequently does, conflict with the best interest of society.

Olson's (1965) work centers on the failure of the memberships of large interest groups such as labor unions, consumer protection groups, or governments to work together to provide themselves with shared goods. Individual members of these groups are better off refraining from collective action even if the goal of that action will benefit the group. This is true because, as long as others cooperate, the benefits of collective action (e.g., better working conditions, safer commodities, or paved roads) will be obtained by all regardless of individual effort or expenditure. If others do not cooperate, on the other hand, no public good will be obtained, and individual actions aimed at realizing that good will fail.

Hardin (1968) described a similar conflict between individual and group interest known as "the tragedy of the commons." The commons are public pasturelands, and the tragedy they represent is that individual shepherds are motivated to add as many animals as possible to their stock even though similar actions by other shepherds will result in overgrazing, Each individual shepherd is faced with the decision of whether or not to increase the size of his or her herd. If other shepherds maintain moderate 
size herds, then the individual shepherd can increase the size of his or her herd without overgrazing the commons. If other shepherds increase the size of their herds, however, then the commons will soon be overgrazed regardless of the actions of any lone shepherd. In either case, each individual shepherd is best off increasing the size of his or her herd. When everyone follows this course of action, however, the depletion of the commons is ensured, and all suffer.

Both Olson's "problem of collective action" and Hardin's "tragedy of the commons" are social dilemmas. These dilemmas are characterized by three features. First, there is some public good to be obtained, or maintained, through collective effort. Second, obtaining or maintaining the public good is costly to the individual in terms of resources or lost opportunity but is not as costly as the failure to obtain or maintain the public good. Third, the behavior of a single individual is not sufficient either to maintain or to ruin the public good. In any situation characterized by these three features, it is in the individual's rational self-interest not to contribute to the public good. This is so whether or not others contribute, and the logic of it follows the familiar pattern of N-person prisoner's dilemmas.

The features of social dilemmas outlined above are common to many of society's problems. Voter apathy, overpopulation, pollution, and the depletion of nonrenewable resources are all types of social dilemmas. The solutions to social dilemmas, then, are of immense practical importance. Unfortunately, current social-psychological research on these dilemmas has not provided many adequate means of solving them. In this article, we argue (a) that most of the current research on social dilemmas reflects an egoistic bias on the part of social psychologists, (b) that this bias limits the number and types of solutions to social dilemmas that psychologists investigate, (c) that egoistically based solutions to social dilemmas are not adequate in many real-world dilemma situations, and (d) that adequate solutions to real-world social dilemmas may be found in nonegoistic motives.

\section{The Egoistic Bias in Social Dilemma Research}

Most of the social-psychological research on solutions to social dilemmas falls under one of three general approaches to promoting cooperation--a behavioral approach, a cognitive approach, or a social approach (Schroeder, 1983). Each of these approaches is based on external rewards that appeal to people's individualistic, egoistic motives. The behavioral approach to promoting cooperation in social dilemmas involves rewarding cooperative behavior and punishing noncooperative behavior (e.g., Kelley \& Grzelak, 1972; Schroeder, Hill, \& Johnson, 1982; Stern, 1976). The idea behind these manipulations is "to provide positive or negative incentives to individuals so that group-oriented behavior becomes more individually rational" (Stern, 1976, p. 1286). 
The cognitive approach to inducing cooperation in social dilemmas involves emphasizing the long-term consequences of noncooperative behavior (e.g., Brechner, 1977; Cass \& Edney, 1978; Edney \& Harper, 1978; Schroeder, Jensen, Reed, Sullivan, \& Schwab, 1983; Stem, 1976). This approach is based on an identification of social dilemmas with what Platt (1973) called "social traps" Social traps are situations (similar to fish traps) in which individuals and societies get started in a direction that later proves unpleasant but from which it is difficult to retreat. From this perspective, social dilemmas are seen as embodying a conflict between the individual's short-term and long-term interests_9 Making individuals aware of the long-term consequences of competition in these situations is thought to promote cooperative behavior.

The third, and most popular, strategy that social psychologists use in producing cooperation in mixed-motive, nonzero-sum games is to change the social environment of the dilemma situation. Manipulations that fall under this strategy include requiring public versus private game decision (e.g., Fox \& Guyer, 1978; Jerdee \& Rosen, 1974), increasing communication with others (e.g., Brechner, 1977; Dawes, McTavish, \& Shaklee, 1977), and decreasing group size (e.g., Komorita \& Lapworth, 1982; Marwell \& Schmidt, 1972). The reasoning underlying these different manipulations is varied, but it is almost always based on an egoistic conception of human nature. Three examples of this egoistic reasoning are presented below.

First, Jerdee and Rosen (1974)justified their manipulation of the visibility of individual decisions by suggesting that "if individual members can be convinced that social acceptance and approval are dependent on behavior in the common interest, perhaps these contingencies can outweigh other more tangible short-run incentives for self-seeking behavior" (p. 713). This is clearly just a social variant of the behavioral approach. Second, according to Dawes et al. (1977), at least one possible reason that communication increases cooperation in social dilemmas is that "the relevant information raised through discussion ....could persuade group members to cooperate" (p. 3). This reasoning, like the cognitive approach, is egoistic because it assumes that learning about dilemmas will cause people to consider their long-term self-interests and avoid the trap of mutual competition. Finally, Komorita and Lapworth (1982) argued that one reason that decreasing group size might increase cooperation in social dilemmas is that "in a large group, an individual's choice has little effect on the final outcome.., but in a small group a person's choice has a much larger effect" (p. 488). This reasoning is based on the idea that if an individual's behavior can affect the outcome of the dilemma, it is in his or her self-interest to cooperate and obtain the public good. 


\section{The Limitations of the Egoistic Bias}

Social psychology's egoistic bias has been pointed out in other contexts (Campbell, 1975; Hogan \& Emler, 1978; Lynn \& Oldenquist, 1984; Wallach \& Wallach, 1983), but in perhaps no other domain is that bias more limiting than in the study of social dilemmas. From an individualistic, egoistic perspective, social dilemmas can be solved only by altering either in fact or in people's minds one or more of the three conditions that define social dilemmas. It is usually neither possible nor desirable to change the fact that there are public goods to be obtained and maintained, so an egoistic perspective really suggests only two ways to solve social dilemmas. First, social dilemmas may be solved by minimizing the net costs of acting for the public good. People can, for instance, be induced to cooperate in social dilemmas if cooperative behavior is rewarded or if noncooperative behavior is punished. Second, social dilemmas may be solved by convincing people that their cooperative individual actions are necessary to ensure the public good. If people think that they can influence the outcome of a social dilemma, then they will be motivated to act cooperatively, because "free riding" pays only when the individual's action does not ruin the public good that is at stake.

Attempts to induce cooperative behavior in social dilemmas by emphasizing the consequences of mutual competition are based on faulty reasoning. Social dilemmas do involve a conflict between the individual's short-term and long-term self-interests, but they also involve the inability of individual actions to avert the long-term consequences of competitive behavior by others. These long-term consequences of others' competitive behavior should not concern the individual because he or she has little control over them. Consistent with this criticism is the fact that empirical tests have generally failed to support the cognitive approach (Brechner, 1977; Cass \& Edney, 1978; Edney \& Harper, 1978; Schroeder et at., 1983).

Some recent attempts to show that cooperation in dilemma situations is in one's interest work only in situations very different from social dilemmas. Axelrod (1984), for example, showed that in iterated prisoner's dilemma competitions by computers, always starting by cooperating and then doing whatever the opposing player did the round before ("tit-for-tat") optimizes a player's outcomes and leads to cooperation. Axelrod's competitions involved (a) only two players at a time, (b) players with equal power, (c) players with knowledge and memory of their opponent's previous behavior, and (d) repeated interactions between players. Under these conditions, individuals can determine dilemma outcomes and maximize their interests by using future cooperation as a reward for their opponent's present cooperation. By definition, these conditions are not met in social dilemmas, because in social 
dilemmas outcomes depend on the joint effects of many people's behavior, not on individual behavior. Furthermore, in many social dilemmas, individual actions are not public and people's interactions with others are not iterated. For example, if one uses more than one's share of gas in a shortage, the act is often secret and its effects inconsequential. Similarly, if one runs a bad tourist restaurant and needs only to get each customer once in order to prosper, then the transaction is not iterated. In these social dilemma situations, individual actions do not affect dilemma outcomes, and "tit-for-tat" is not an effective policy.

\section{The Problems with Egoistic Solutions to Social Dilemmas}

The only two methods of promoting cooperation in social dilemmas that are possible from an individualistic, egoistic perspective (i.e., reducing the net costs of cooperation through material or social rewards and punishments and convincing people that their behavior will affect the dilemma outcome) are inadequate in many real-world dilemma situations. The problems with these solutions will be discussed further.

Materially rewarding cooperative behavior and punishing noncooperative behavior has proven effective in eliciting cooperation in social dilemmas (Kelley \& Grzelak, 1972; Schroeder et al., 1982; Stern, 1976). These solutions remove the social dilemmas by simply making it in the individual's interest to cooperate, but their use entails several problems. First, inducing cooperation through material rewards and punishments would require so many police and watchers that the general quality of life would be severely jeopardized. Second, these solutions utilize resources that might be used elsewhere. For example, the use of government incentives to keep farmers from overproducing certain crops prevents the use of those funds for other purposes. A third problem with promoting cooperation through material rewards and punishments is that this cooperative behavior extinguishes rapidly when the incentives are removed (Schroeder et al., 1982). This means that these resolutions of social dilemmas must be either short-run solutions or continuous drains on society's resources and civil liberties. Clearly, alternative solutions are needed.

Of course, rewards for cooperative behavior and punishments for noncooperative behavior need not be materialistic. Social approval or disapproval may also be used to promote cooperation in social dilemmas. Laboratory attempts to use social rewards and punishments by manipulating the identifiability of individual decisions, however, have proven only marginally effective (Fox \& Guyer, 1978; Jerdee \& Rosen, 1974). Perhaps the concern with social disfavor in these situations is weak because people expect others to act noncooperatively and thus to share the public disfavor. Even if 
expectations of shared and diluted social disfavor could be avoided, the use of social rewards and punishments would be effective in only a few real-world dilemma situations. In many social dilemma situations it would be extremely difficult to identify and publicize individual attempts at free riding. Obtaining and publicizing information about individuals' home consumption of water, gas, and electricity would be next to impossible, for instance, both because it would violate people's rights to privacy and because of the sheer number of people who would have to be monitored.

Equally difficult is convincing people that their decisions can affect the outcome of social dilemmas. The manipulation of group size (e.g., Komorita \& Lapworth, 1982; Marwell \& Schmidt, 1972) in laboratory games may increase cooperation because it changes people's perceptions of their own effectiveness, but it is not possible to manipulate the size of the groups facing real-world social dilemmas. Nor is it likely that persuasive campaigns could convince people that their behavior would affect the outcome of social dilemmas, mainly because such assertions would be patently false. Research on this topic seems to be unavailable, but it is plain that attempts to persuade people that one vote will determine a statewide election or that an individual's consumption of gasoline will significantly affect the supply are unlikely to succeed.

\section{Nonegoistic Solutions to Social Dilemmas}

Egoistic motives seldom provide adequate solutions to social dilemmas. Viable solutions to these dilemmas may be found, however, in nonegoistic motives. We use the term nonegoistic motives to refer to desires that are independent of external reinforcements such as monetary rewards or social approval and that are not proven to depend on any kind of self-gratification. There are three types of nonegoistic motives (and behaviors)--altruistic motives, group-egoistic motives, and moral motives. Each of these will be discussed in detail.

The terminology just outlined is slightly atypical in that we use altruism to denote just one kind of nonegoistic motive. Social psychologists generally lump all putative nonegoistic behavior under the term altruism (c.f. Rushton \& Sorrentino, 1981), although there is debate over the definition of the term. Some researchers define altruism as behavior aimed at helping others without anticipation of external rewards (e.g., Macauley \& Berkowitz, 1970; Schwartz \& Howard, 1981), while implying, or at least not rejecting, a dependence on anticipated internal rewards. Other investigators insist that altruism is behavior aimed at helping others without anticipation of internal or external rewards (e.g., Batson, Duncan, Ackerman, Buckley, \& Birch, 1981; Krebs \& Russell, 1981). We understand altruism and the other kinds of nonegoistic behavior in the latter sense, but the thesis of this article does not depend on 
this definition. As previously noted, psychologists' research attempts to induce cooperation in social dilemmas have relied on external rewards such as material goods and social approval. What we are advocating is an investigation into and use of other types of cooperative motivation. These other motives (i.e., altruistic motives, group-egoistic motives, and moral motives) may provide solutions to social dilemmas regardless of whether they are based on anticipated internal gratifications.

\section{Altruistic Motives}

Altruistic motives are nonegoistic desires to help other people. Several investigators have linked these desires to empathetic emotion (e.g., Coke, Batson, \& McDavis, 1978; Hoffman, 1975; Krebs, 1975). According to these researchers, observing another's need produces vicarious arousal in the observer. If this vicarious arousal is correctly identified as stemming from the plight of the person in need, then the observer will experience empathetic emotion and will, if possible, seek to help the person. Psychologists are divided about whether empathy produces helping by creating a selfless concern for the person in need or by creating a desire to reduce the empathizer's own vicarious arousal (Batson et al., 1981; Hoffman, 1981). In either case this empathetic motivation for helping stems from internal processes independent of external reward.

Altruistic motives can probably not be relied on to produce cooperative behavior in social dilemmas. Although much of the current aid to Ethiopia is undoubtedly motivated by empathy, this situation is not a pure social dilemma. Contributions to famine relief organizations, although individually ineffective in eliminating the famine and its general impact, are individually effective in temporarily eliminating the hunger of a few people. This ability to aid others effectively is not present in pure social dilemmas such as those dealing with voting in an election, using gas in a shortage, or throwing trash on the highway. It is doubtful that altruism would motivate costly and ineffectual behavior in these dilemma situations.

\section{Group-Egoistic Motives}

Group-egoistic motives are nonegoistic desires to serve those groups and social institutions that are the objects of one's love and loyalty. These motives stem from a sense of community (Gemeinschaft)--that is, from a sense of identification with, and possession of, social units that are viewed as one's own. Examples of such social units are one's family, neighborhood, organization, and country. Group loyalty or community is a collectivistic, anti-individualistic sentiment that has been discussed by numerous authors, classically by Durkheim ( 1951) and more recently by Bellah, Madsen, Sullivan, Swidler, \& Tipton (1985), Knowles (1982), and Oldenquist (I 982). The existence and importance 
of this sense of community has been demonstrated by several investigators. It has been found, for example, that people identify with their group's success even when their contribution to that success is small (Cialdini, Borden, Thorne, Walker, \& Freeman, 1976) and that feedback about group performance can have more impact on people than feedback about their own performance (Zander \& Armstrong, 1972).

Messick and Brewer (1983) have argued that this identification with a group can lead to cooperative behavior in social dilemmas because it "makes it less likely that individuals will make sharp distinctions between own and others' welfare" and because it "may also increase the perceived effectiveness of individual actions" (p. 28). Although we doubt that group identification is likely to affect the perceived effectiveness of individual actions in social dilemmas, we agree that group identification may lead to cooperative behavior in these dilemmas. Group loyalty, we suggest, produces both a desire to see the group succeed and a separate desire to serve and contribute to the group. Group-egoists, then, may act cooperatively in social dilemmas even though their actions are not decisive because they want to make some contribution (no matter how small) as a symbol of their membership in and support of their own neighborhood, country, and so forth.

Although Messick and Brewer (1983) have suggested that group identification might provide a means of promoting cooperation in social dilemmas, very little research has been conducted to test this hypothesis. The only such studies of which we are aware were conducted by Kramer and Brewer (1984). In three separate experiments, these investigators found that manipulations of group identification led to greater conservation in a replenishable resource game. These studies support the utility of groupegoistic motives in producing cooperative dilemma behavior and argue for the necessity of more research on these motives.

\section{Moral Motives}

Moral motives are nonegoistic desires to obey moral principles. There is some disagreement in psychology about the specific nature of moral principles and about how they affect behavior. Cognitive developmentalists (e.g., Kohlberg, 1981, 1984) see moral principles as propositions with formal properties such as universality. These theorists have no clear position on the motivational processes underlying moral behavior. Kohlberg took a cold, cognitive position, arguing that moral principles affect behavior by defining rights and duties in a situation. He provided no indication, however, of why people comply with these rights and duties (except to deny that such compliance is affectively based). Sociallearning theorists (e.g., Aronfeed, 1968; Bandura, 1971) and others (e.g., Freud, 1965; Hogan, Johnson, 
\& Emler, 1978; Schwartz \& Howard, 1981) see moral principles as internalized social norms. According to some of these theorists, people comply with moral principles because they have learned to reward themselves for moral actions and to punish themselves for immoral ones. According to others of these theorists, people comply with moral principles because they value the principles independently of any self-gratification that compliance may bring. Despite their differences, however, all of these positions distinguish moral motives from motives based on external rewards and punishments.

Moral motives may lead people to cooperate in social dilemmas, because moral principles generally advocate cooperative, nonselfish behavior. Moreover, moral principles are binding even in situations where individual actions have minimal consequences, because they imply the relevance of the question, "What if everyone (or no one) acted like that?" Psychological research has demonstrated that moral beliefs influence people's prosocial intentions and behaviors (Pomazal \& Jaccard, 1976; Schwartz, 1973; Zuckerman \& Reis, 1978), but psychologists interested in social dilemmas have largely ignored moral motives. The only exception of which we are aware are two unpublished studies by Dawes, Shaklee, and Talarowski (in Dawes, 1980). These authors found that a "938 word sermon about group benefit, exploitation, whales, ethics, and so on" (p. 188) significantly increased subjects' cooperation in a dilemma game. Unfortunately, these sermons mixed together reasoning, emotional appeals, and social pressure in addition to reflecting the experimenter's rather than the subject's moral beliefs. Moreover, the artificial dilemma situation probably failed to reach real-world levels of temptation to act immorally. These problems are not inherent to an investigation of moral motives in social dilemmas, however, and more sophisticated studies should be conducted in this area.

\section{Conclusion}

Social psychologists have approached the problem of social dilemmas with an egoistic bias that prohibits them from finding many adequate solutions to these dilemmas. However, solutions may be found given a nonegoistic perspective of human nature that appeals to a variety of motives--egoistic, group-egoistic, moral, and sometimes altruistic. The possibility that group-egoistic and moral motives may lead people to act cooperatively in dilemma situations deserves empirical investigation. Also deserving of research efforts are questions about the conditions under which these motives are most effective. The answers to these questions may provide society with the means to resolve the very real social dilemmas it faces. 


\section{References}

Aronfeed, J. (1968). Conduct and conscience." The socialization of internalized control over behavior. New York: Academic Press.

Axelrod, R. M. (1984). The evolution of cooperation. New York: Basic Books.

Bandura, A. (1971). Social learning theory New York: General Learning Press.

Batson, D. C., Duncan, B. D., Ackerman, P., Buckley, T., \& Birch, K. (1981). Is empathetic emotion a source of altruistic motivation? Journal of Personality and Social Psychology, 40, 290-302.

Bellah, R., Madsen, R., Sullivan, W., Swidler, A., \& Tipton, S. (1985). Habits of the heart. Berkeley: University of California Press.

Brechner K. C. (1977). An experimental analysis of social traps. Journal of Experimental Social Psychology, 13, 552-564.

Campbell, D. T. (1975). On the conflicts between biological and social evolution and between psychology and moral tradition. American Psychologist, 30, 1103-1126.

Cass, B. C., \& Edney, J. J. (1978). The commons dilemma: A simulation testing resource visibility and territorial division. Human Ecology, 6, 371-386.

Cialdini, R., Borden, R. J., Thorne, A., Walker, M. R., \& Freeman, S. (1976). Basking in reflected glory: Three (football) field studies. Journal of Personality and Social Psychology, 34, 366-375.

Coke, J. S., Batson, C. D., \& McDavis, K. (1978). Empathetic mediation of helping: A two stage model. Journal of Personality and Social Psychology, 36, 752-766.

Dawes, R. M. (1980). Social dilemmas. Annual Review of Psychology, 31, 169-193.

Dawes, R. M., McTavish, J., \& Shaklee, H. (1977). Behavior, communication, and assumptions about other people's behavior in a commons dilemma situation. Journal of Personality and Social Psychology, 35, 1-11.

Durkheim, E. (1951). Suicide. New York: Free Press.

Edney, J. J., \& Harper, C. S. (1978). The effects of information in a resource management problem: A social trap analysis. Human Ecology, 6, 387-395.

Fox, J., \& Guyer, M. (1978). "Public" choice and cooperation in N-person prisoner's dilemma. Journal of Conflict Resolution, 22, 468- 481.

Freud, S. (1965). New introductory lectures on psychoanalysis (J. Strachey, Ed.). New York: Norton. Hardin, G. J. (1968). The tragedy of the commons. Science, 162, 1243- 1248. 
Hoffman, M. L. (1975). Developmental synthesis of affects and cognition and its implications for altruistic motivation. Developmental Psychology, 11, 607-622.

Hoffman, M. L. (1981). Is altruism a part of human nature? Journal of Personality and Social Psychology, 40, 121-137.

Hogan, R. T., \& Emler, H. P. (1978). The biases of contemporary social psychology. Social Research, 45, 478-534.

Hogan, R. T., Johnson, J. A., \& Emler, H. P. (1978). A socioanalytic theory of moral development In W. Damon (Ed.), Moral development: New directions for child development (Vol. 2, pp. 1-18). San Francisco: Jossey-Bass.

Jerdee, T. H., \& Rosen, B. (1974). Effects of opportunity to communicate and visibility of individual decisions on behavior in the common interest. Journal of Applied Psychology, 59, 712-716.

Kelley, H. H., \& Grzelak, J. (1972). Conflict between individual and common interest in an N-person relationship. Journal of Personality and Social Psychology, 21, 190-197.

Knowles, E. S. (1982). From individuals to group members: A dialectic for the social sciences. In N. Ickes \& E. S. Knowles (Eds.), Personality, roles, and social behavior (pp. 1-25). New York: SpringerVerlag.

Kohlberg, L. (1981). The philosophy of moral development. San Francisco: Harper \& Row.

Kohlberg, L. (1984). The psychology of moral development. San Francisco: Harper \& Row.

Komorita, S. S., \& Lapworth, C. W. (1982). Cooperative choice among individuals versus groups in an Nperson dilemma situation. Journal of Personality and Social Psychology, 42, 487-496.

Kramer, R. M., \& Brewer, M. B. (1984). Effects of group identity on resource use in a simulated commons dilemma. Journal of Personality and Social Psychology, 46, 1044-1057.

Krebs, D., \& Russell, C. (1981). Role-taking and altruism: When you put yourself in the shoes of another, will they take you to their owner's aid? In J. P. Rushton \& R. M. Sorrentino, (Eds.), Altruism and helping behavior (pp. 151-165). Hillsdale, NJ: Erlbaum.

Krebs, K. L. (1975). Empathy and altruism. Journal of Personality and Social Psychology, 32, 1134-1146.

Lynn, M., \& Oldenquist, A. (1984). American social psychologists: The children of Hobbes. Academic Psychology Bulletin, 6, 43-47.

Macauley, J. R., \& Berkowitz, L. (1970). Altruism and helping behavior. New York: Academic Press. Marwell, G., \& Schmidt, D. R. (1972). Cooperation in a three-person prisoner's dilemma. Journal of Personality and Social Psychology, 21, 376-383. 
Messick, K. M., \& Brewer, M. B. (1983). Solving social dilemmas: A review. In L. Wheeler \& P. Shaver (Eds.), Review of personality and social psychology (Vol. 4, pp. 11-44). Beverly Hills, CA: Sage. Oldenquist, A. (1982). Loyalties. Journal of Philosophy, 79, 173-193.

Olson, M. (1965). The logic of collective action: Public goods and the theory of groups. Cambridge, MA: Harvard University Press.

Platt, J. (1973). Social traps. American Psychologist, 28, 641-651.

Pomazal, R. J., \& Jaccard, J. J. (1976). An informational approach to altruistic behavior. Journal of Personality and Social Psychology, 33, 317-326.

Rushton, J. P., \& Sorrentino, R. M. (Eds.). (1981). Altruism and helping behavior. Hillsdale, NJ: Erlbaum.

Schroeder, D. A. (1983). Promoting cooperation in social trap situations. Academic Psychology Bulletin, $5,237-246$

Schroeder, D. A., Hill, G. E, \& Johnson, D. E. (1982). Rewarding conservation and punishing overconsumption: Can the commons be saved? JSAS Catalog of Selected Documents, 12, 7. (MS. No. 2417).

Schroeder, D. A., Jensen, T. D., Reed, A. J., Sullivan, D. K., \& Schwab, M. (1983). The actions of others as determinants of behavior in social trap situations. Journal of Experimental Social Psychology, 19, 522- 539.

Schwartz, S. H. (1973). Normative explanations of helping behavior: A critique, proposal, and empirical test. Journal of Experimental Social Psychology, 9, 349-364.

Schwartz, S. H., \& Howard, J. A. (1981). A normative decision-making model of altruism. In J. P. Rushton \& R. M. Sorrentino (Eds.), Altruism and helping behavior (pp. 189-211). Hillsdale, N J: Erlbaum.

Stern, P. C. (1976). Effect of incentives and education on resource conservation decisions in a simulated commons dilemma. Journal of Personality and Social Psychology, 34, 1285-1292.

Wallach, M. A., \& Wallach, L. (1983). Psychology's sanction for selfishness: The error of egoism in theory and therapy San Francisco: Freeman.

Zander, A., \& Armstrong, W. (1972). Working for group pride in a slipper factory. Journal of Applied Social Psychology, 2, 293-307.

Zuckerman, M., \& Reis, H. T. (1978). Comparisons of three models for predicting altruistic behavior. Journal of Personality and Social Psychology, 36, 498-510. 